\title{
Left bundle, right diagnosis
}

\author{
A. E. Schaafsma $\cdot$ C. Coolsma $\cdot$ H. Lameijer
}

Published online: 1 March 2019

(C) The Author(s) 2019

\section{Answer}

The partial electrocardiogram (Fig. 1) shows a left bundle branch block (LBBB), possibly caused by acute coronary syndrome (ACS). However, it can also be preexistent, or based on other cardiac disease. To evaluate ACS in patients with LBBB, the Sgarbossa criteria should be used [1]. Sgarbossa criteria comprise three electrocardiographic criteria for diagnosis of ACS in patients with LBBB: ST-segment elevation of $1 \mathrm{~mm}$ or more that is concordant with the QRS complex; STsegment depression of $1 \mathrm{~mm}$ or more in leads V1, V2, or V3; and ST-segment elevation of $5 \mathrm{~mm}$ or more that is disconcordant with (in the direction opposite) the QRS complex. Each criterion increases the chance of ACS in patients presenting with LBBB. Smith et al. modified these criteria by replacing the third criterion with an ST/S ratio less than -0.25 , improving the diagnosis of STEMI in these patients [2].

In this electrocardiogram, LBBB with ST depression in V2-V4 in the anterior leads is observed. This observation, in combination with the patient's complaints, is sufficient reason to consider a STEMI equivalent. The patient was treated with heparin 5,000 IE (intravenous route), acetylsalicylic acid $500 \mathrm{mg}$ and ticagrelor $180 \mathrm{mg}$ and nitroglycerine (intravenous route).

Emergency coronary angiography showed a significant stenosis of both the left main and right coronary artery, not accessible for percutaneous coronary intervention. The patient was treated with emergency coronary artery bypass grafting.

Conflict of interest A.E. Schaafsma, C. Coolsma and H. Lameijer declare that they have no competing interests.

Open Access This article is distributed under the terms of the Creative Commons Attribution 4.0 International License (http://creativecommons.org/licenses/by/4.0/), which permits unrestricted use, distribution, and reproduction in any medium, provided you give appropriate credit to the original author(s) and the source, provide a link to the Creative Commons license, and indicate if changes were made.

\section{References}

1. Sgarbossa EB, Pinski SL, Barbagelata A, et al. Electrocardiographic diagnosis of evolving acute myocardial infarction in the presence of left bundle-branch block. N Engl J Med. 1996;334(8):481-7.

2. Smith SW, Dodd KW, Henry TD, et al. Diagnosis of STelevation myocardial infarction in the presence of left bundle branch block using the ST-elevation to S-wave ratio in a modified Sgarbossa rule. Ann Emerg Med. 2012;60:766-76.

A. E. Schaafsma $\cdot$ C. Coolsma $\cdot$ H. Lameijer $(\bowtie)$

Department of Emergency Medicine, Medical Centre

Leeuwarden, Leeuwarden, The Netherlands

heleen.lameijer1@znb.nl 


\title{
Advertisement placed here.
}

\author{
ces bohn \\ CL van loghum
}

Houten 2019 


\title{
Advertisement placed here.
}

\author{
ces bohn \\ CL van loghum
}

Houten 2019 


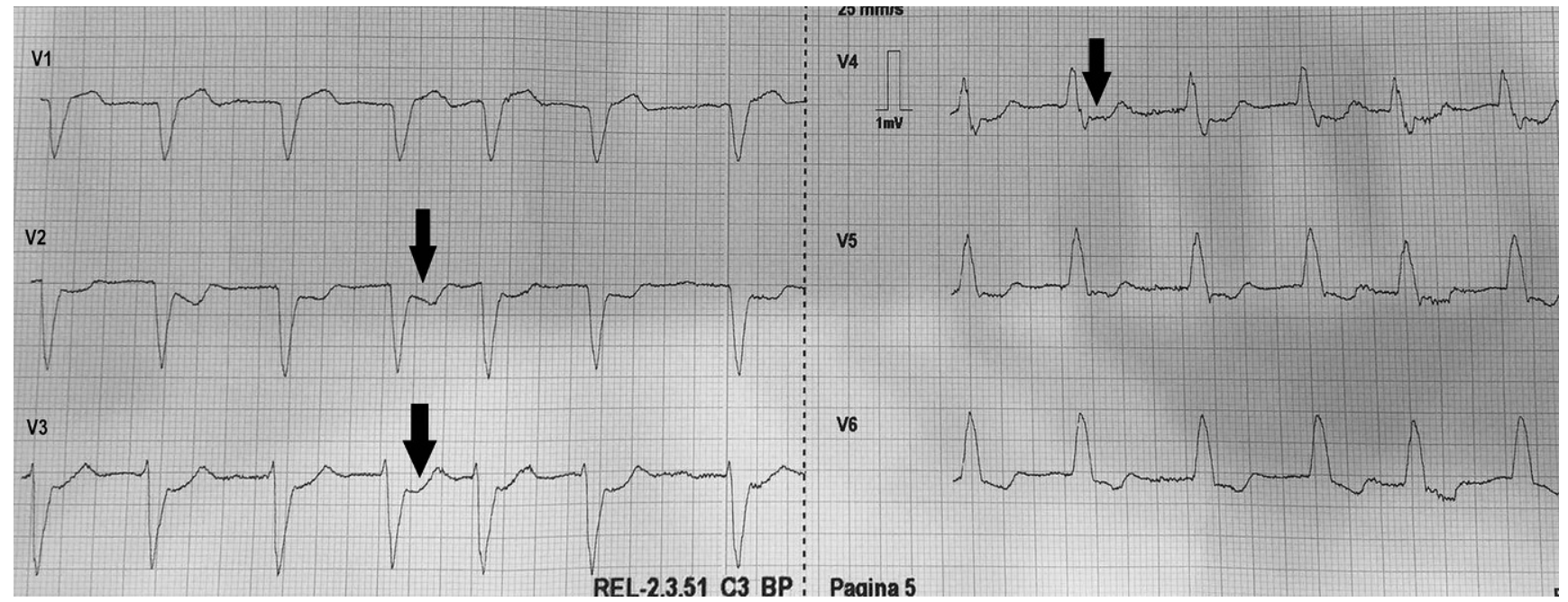

Fig. 1 The ECG as in Fig. 1 of the rhythm puzzle question, showing LBBB with ST depression in V2-V4 in the anterior leads (arrows), which is a Sgarbossa criterion. ECG electrocardiogram, LBBB left bundle branch block 